\title{
ARTICLE
}

\section{Impact of parents' substance misuse on children: an update}

\author{
Richard Velleman \& Lorna J. Templeton
}

\begin{abstract}
Richard Velleman is Emeritus Professor of Mental Health Research, University of Bath, and Senior Research Fellow, Sangath, Goa, India. He is a clinical psychologist who founded and managed the Mental Health Research and Development Unit (a joint university/National Health Service (NHS) research \& development unit), as well as statutory addictions and other services, helped develop the families and psychosis service within Avon and Wiltshire Partnership Mental Health NHS Trust, worked as an NHS Trust Board Director, and published widely on a range of mental health topics, especially related to the impact of addiction on families. Richard is a Trustee for the Addiction and the Family International Network (AFINet). Lorna J. Templeton is an independent research consultant and a Visiting Fellow at the University of Bath. She has been conducting research in the area of addiction and the family, including parental substance misuse, for more than 15 years. She has co-authored one book, authored or co-authored many book chapters and peerviewed articles. Lorna is a Trustee for Adfam and AFINet. Correspondence Professor Richard Velleman, Department of Psychology, University of Bath, Bath BA2 7AY, UK. Email: R.D.B.Velleman@bath.ac.uk
\end{abstract}

\begin{abstract}
SUMMARY
We review how research over the past decade both supports existing knowledge about the risk factors that children in the UK affected by parental substance misuse face, and adds to our knowledge about the protective factors, protective processes and evidence of resilience which can reduce the likelihood that children will experience poor outcomes. Further research is needed to understand what areas of resilience are most important to target and how other variables, such as gender or age, may influence how protective factors affect the development of resilience. Longitudinal research is also needed to better understand how an individual's resilience may change over time. Finally, there remain many considerable challenges which practitioners, service providers, commissioners and policy makers face in better meeting the needs of this population of children.
\end{abstract}

\section{LEARNING OBJECTIVES}

- Understand effective mechanisms for reducing risk, developing protective factors and building resilience in children affected by parental substance misuse

- Be able to focus on the child's needs, not the parental problems, and on maximising the necessary beneficial factors in their lives

- Be able to incorporate the ideas within this article into clinical and therapeutic practice

\section{DECLARATION OF INTEREST}

None

In a previous article in BJPsych Advances we summarised the research on the impact that parental substance misuse has on children and on resilience (Velleman 2007a). Nearly 10 years on, we have been asked to update what more is now known about building resilience in children affected by parental substance misuse, drawing on the wider literature where relevant. We briefly consider prevalence, impact and risk factors, before concentrating on recent findings and emerging understanding relating to protective factors/ processes and to resilience. We also examine what practitioners and services can do, and are doing, to modify the impact of parental substance misuse on children. Finally, we clarify what has been learned over the past decade and what gaps remain.

\section{Prevalence of parental substance misuse and problems}

Estimates of the number of parents and children who were believed to be affected by these problems have risen considerably since 2007 , with approximately 3.4 million children under 16 living with at least one binge-drinking parent, almost a million living with two binge drinkers, and almost half a million living with a lone parent who is also a binge drinker; a further 2.6 million live with a hazardous drinker, 300000 with a harmful drinker and $>700000$ with a dependent drinker (Manning 2009, 2011; Hill 2013).

Regarding illicit drugs, almost a million children live with an adult who has used any illicit drugs within the previous year, $>250000$ live with an adult who has used a class A illicit drug within the previous year, and $>870000$ live with an adult who has used a class $\mathrm{C}$ illicit drug within the previous year. In terms of drug dependence, 335000 children live with a drug-dependent user, 72000 with an injecting drug user, 72000 with a drug user in treatment, and 108000 with an adult who had overdosed.

About 430000 children live with a problem drinker who also uses drugs, and >450000 have parents where problem drinking coexists with mental health problems. Furthermore, high numbers of children live with a parent with more than one problem (alcohol/drugs/mental health difficulties), and more than $25 \%$ of babies under the age of 1 will have been exposed to at least one type of serious risk in their first 12 months (problem drinker, class A drug user, mental health disorder or victim of domestic violence). There has also been growing concern about the emergence and increasing use of a range of novel psychoactive substances ('legal highs') in this time (European Monitoring Centre for Drugs and Drug Addiction 2015).

\section{The impact on children}

As summarised in our 2007 article, exposure to parental substance misuse can have numerous negative consequences for young people. More recent evidence again corroborates these 
conclusions. Among the negative effects that have been recorded are:

- emotional and mental health problems, including depression, anxiety disorders, obsessive-compulsive disorder and attachment-related psychological adjustment (Fraser 2009; Harwin 2010)

- difficulties in dealing with the knock-on effects of parental substance misuse - emotions, silence, trust and stigma (Templeton 2009; Houmoller 2011; Hill 2013, 2015)

- the development of alcohol and drug problems in adolescence and beyond (Harwin 2010; Houmoller 2011)

- early sexual relationships and relationship difficulties later in life (Harwin 2010; Kelley 2010)

- academic underachievement (Torvik 2011)

- conduct and behavioural problems (Harwin 2010).

Cleaver et al (2011), building on their earlier work in this area, helpfully summarise how children of different ages can experience different problems when exposed to a range of parental problems, including parental substance misuse.

\section{Risk}

There are two main pathways through which children are at increased risk of poor outcomes: one dictated by the parenting and wider family environment, and the other influenced by children's exposure to additional risks. Our 2007 article showed the range of factors in parents' lives and relationships which have the potential to exacerbate their children's problems, and that these have a cumulative effect: the more that are present, the higher the risk of negative outcomes (Velleman 2007a). Further evidence has emerged to corroborate and strengthen these findings.

A number of researchers (Velleman 2008; Bernays 2011) have reported that disharmony, aggression and violence significantly raise the risk of negative outcomes for children in families who misuse substances. Evaluation of calls to ChildLine and the National Association for the Children of Alcoholics indicates that children who disclose that they are living with parental alcohol (or drug) misuse often have another major problem which is troubling them and which is the initial reason for making the call (most commonly physical abuse, violence or family breakdown) (Mariathasan 2010). Research into UK social work case-loads has revealed the significant interplay between substance misuse and child protection concerns, and their coexistence with problematic parenting, conflict and domestic violence (e.g. Cleaver 2007; Forrester 2007; Brandon 2009, 2010; Munro 2011).
Similarly, a number of researchers have corroborated the finding that the existence of problematic parenting or the absence of a stable adult figure also significantly raises risks for children in both the short and long term (Cleaver 2007; Redelinghuys 2008; Scaife 2008; Hill 2013, 2015).

Finally, Adamson \& Templeton (2012), Cleaver et al (2011), Horgan (2011) and Templeton (2013) have all reviewed literature showing the cumulative increased risk of poor outcomes when children face multiple adversities in addition to parental substance misuse (see also Jaffee et al (2007) for a 'cumulative stressors model').

However, children and families are unique, so rules about risks and outcomes are often not generalisable: it is unhelpful to look for specific and linear links between a particular problem/risk factor and a particular negative outcome. What is clear is that risks are greater if:

- there is exposure to multiple problems (the presence of domestic violence and abuse appears to be particularly potent)

- the child lives with two parents with problems

- there is greater length and severity of the problems

- there is significant 'fall out' associated with problems, both within the family (e.g. disharmony) and outside (e.g. significant disruption, association with the criminal justice system).

The key points relating to the range of risk factors which children of problem substance misusers face are shown in Box 1.

\section{Protection}

It is easy to understand why many children who grow up in such environments are at risk of negative outcomes. Yet there is considerable evidence that children can grow up in all sorts of difficult circumstances without developing significant problems, and that they sometimes demonstrate good outcomes, in spite of such serious threats to adaption and development. We reviewed this evidence in the 2007 article, but much more is now understood.

Protective factors are now seen as being of major importance. They appear to work in a number of ways:

- they serve to balance out risk factors;

- some are inconsistent with their opposite: if the protection factor is there, the risk factor cannot be (e.g. being a consistent parent is not compatible with being an inconsistent one);

- some also appear to have major protective features in their own right - the presence of a stable adult figure can serve as protection even if other elements of a child's life are very risky. 
BOX 1 Risk factors for children of problem substance users: key points

- All areas of a child's life can be negatively affected by parental problematic substance use and children are at risk of a wide range of poor outcomes across all domains in both the shortand the long-term.

- Children can be affected by the cyclical and relapsing nature of their parents' substance use and problems.

- Risks are significantly exacerbated when parental substance use and misuse is accompanied by parental mental illness and/ or domestic violence, both of which frequently coexist with substance misuse.

- Wider environmental risk factors include poverty and socioeconomic disadvantage, discrimination, housing, social exclusion, unemployment and public health concerns. Often many of these wider risk factors also coexist.

- Risk factors arise at each of the individual, parental, familial and environmental levels. No two children (and no two families) are the same. Siblings are affected differently. This means that although there are clear probabilistic associations between various risk factors and poor outcomes, these associations are not straightforward or generalisable for any given child.

- Children are at greater risk when multiple problems are present. This risk is cumulative according to how many problems or risk factors a child is exposed to. The duration and severity of the problems also influence how a child is affected.

- Parental problematic substance use and other parental problems (e.g. domestic violence) and wider environmental factors (e.g. social exclusion) can greatly affect parenting, relationships and attachments between parents and children, and everyday family life. Conflict, disharmony, and family separation and breakdown are common. The literature suggests that children can be more affected by these issues than they are by the problems themselves.

- How children are affected is influenced by variables such as gender, age, development and culture. The presence of problems in a child's early years and at key developmental stages or transition periods is thought to be particularly influential.

- Parental gender influences how a child is affected, although more research has been undertaken on the impact of maternal $v$. paternal problems and the impact on mothering $v$. fathering.

- Parental and family problems often lead to an atmosphere in the home of fear, chaos, uncertainty, secrecy and stigma of living with these problems; and these can also act as barriers to seeking help. It can be hard for children to understand and articulate what they are experiencing and feeling, and what they need. They may also avoid talking to others because they remain loyal to and protective of their parents.

- The presence of domestic violence is believed to be a particularly significant risk factor.

(Based on Templeton, 2013: pp. 82-83)
The complexities of protective factors and how they interact with risky ones are further discussed later in this article (see Resilience).

Nevertheless, there have not been many studies undertaken into protective factors and their relationship with resilience specifically with children living with parental alcohol/substance misuse. Three important and more recent qualitative studies in this area are from the USA (Moe 2007), Israel (Ronel 2011) and Scotland (Backett-Milburn 2008). All three studies talked directly to children and young people, who offered their perspective on what might be important protective factors which can create resilience. The Backett-Milburn et al study (2008) is also important because it draws out some complexities in this area. For example, the authors highlight that identified coping strategies and support could be 'a double-edged sword', further stressing that, 'the protective factors classically thought to promote resilience were seldom in place for these children unconditionally and without associated costs'. Again, Cleaver et al (2011) list the key protective factors which might be most likely to influence children of different ages.

These and other studies have also drawn attention to the 'active agency' which children/young people possess in adopting coping strategies, seeking support, and choosing what they share about their circumstances and with whom (Backett-Milburn
2008; Holmila 2011; O’Connor 2014; Hill 2015). For example, Hill's qualitative study with 30 children/young people (aged between 9 and 20 years) in Scotland highlighted that, 'a failure to talk is often seen as a deficit, rather than as an active choice by some children and young people that should be respected' (Hill 2015). Accepting such agency by children and young people, and the protective role that this may have for them, is an important addition to understanding this area, and should be incorporated into service models.

Although some of this more recent research focuses on internal protective characteristics it is still the case that protective factors located within the family, particularly in terms of parenting and parent-child relationships, seem to be central. The early years and key stages of a child's development appear to be critical times at which children can be at increased risk of poor outcomes and when a protective factor or process can be most influential. In addition, the importance of external support needs to be acknowledged. The Kauai Longitudinal Study on Hawaii reported that, by age 32 years, those who coped effectively with the trauma of parental alcohol misuse had significantly larger numbers of people in their support networks than those who had problems coping (Werner 2004).

The key protective factors in various domains, as revealed in the literature reviewed in this article, are summarised in Box 2. 
BOX 2 Protective factors and resilience in children affected by parental substance misuse, as revealed in the literature

\section{Individual factors}

- Internal locus of control - a sense that they can make a difference to their circumstances and have the power to change their situation

- 'Active agency' in adopting coping strategies, seeking support and choosing what to share about their circumstances and with whom ${ }^{\mathrm{a}}$

- Personal qualities and social skills (e.g. expression of feelings, knowledge, life choices, self-reflection, easy individual temperament/disposition, emotional regulation, self-efficacy)

- Having a hobby or a creative talent or engagement in outside activities or interests (e.g. sport, singing, dancing, writing, drama, painting) - anything that can provide an experience of success and/or approbation from others for the child's efforts

- Self-monitoring skills and self-control

- Coping and problem-solving skills - ability to think about and make decisions about coping

- Plans for the future/yearning for a better future

- Intellectual capacity

- A sense of humour

- Sense of self-strength relative to substance-dependent parent. Resisting over-identification with, and maintaining psychological separation from, parental problem

- Perceptions of 'substance misuse' behaviour. Good knowledge and understanding of the parental problem(s)

- Not taking drugs or drinking

- Achieving a balance between supporting the parent(s) and looking after themselves

- Religion or faith in God

\section{Family factors}

General

- Supporting and trusting relationship with a stable (non-substance misusing) adult (e.g. uncles, aunts, grandparents)

- Close positive bond with at least one adult in a caring role (e.g. parents, older siblings, grandparents)

- Early and compensatory experiences and a good relationship with primary carer(s) in first years of life; low levels of separation from the primary carer in the first year of life

- Demonstration of affection from members of extended family

- Parental self-efficacy and good parental self-esteem

- Family observing traditions and rituals (cultural, religious, familial)

- Consistency and stability in everyday family life (e.g. social life, rituals, roles, routines); families spending time together

- Openness and good communication within the family, including open and appropriate discussion of family problems

- Child having family responsibilities

- Small family size, larger age gaps between siblings

- Adequate finances and employment opportunities/income; good physical home environment

- Constructive coping styles and deliberate parental actions to minimise adversity for children

- Knowledge of protective factors

- Strong family norms and morality
- Characteristics and positive care style of parents (a balance between 'care' (parental support, warmth, nurturance, attachment, acceptance, cohesion, and love) and 'control' (supervision, monitoring, clarity about family rules and boundaries, parental discipline, punishment))

- Parents having high expectations of the child, and clear and open communication of both expectations (about alcohol use/non-use and also generally) and potential disapproval if expectations are not met

- Parental modelling of the behaviours expected of or wished for from their children

- Absence of domestic violence/abuse, family breakdown and associated losses

Specific to parental substance problems

- Parental problems are of mild intensity and shorter duration

- One parent does not have problems

- Parent is receiving treatment

- Drug paraphernalia, activity and associates are kept away from children

- Substance misuse occurs away from the home

Community/environmental factors

- Cultural connectedness, values and identity

- Support from an adult/adult role model (e.g. teacher, neighbour)

- Strong friendships and relationships with peers, including those who a young person can talk to about the problems at home

- Living in a community where there is a sense of caring, mutual protection

- Community engagement and supportive social networks; strong bonds with local community/community involvement

- Positive school experiences and influences; opportunities through education and employment - out-of-school/community activities

- Attendance at school, achievement, monitoring of progress and acknowledgement of success

- Teachers' expectations and discipline

- Positive opportunities at times of life transition

- Support from key community services such as healthcare

Evidence of resilience that these protective factors encourage

- Deliberate planning by the child that their adult life will be different

- 'Active agency': see Individual factors ${ }^{\mathrm{a}}$

- High self-esteem and confidence

- Good self-efficacy

- A sense of direction or mission

- Skills (both verbal and cognitive) and values that lead to good use of personal abilities to achieve

- A range of problem-solving skills

- An ability to deal with change

- Feeling that there are choices

- Feeling in control of own life

- Previous experience of success and achievement

- Feeling safe and secure, loved and cared for

- An ability to play

a. 'Active agency' is both a protective factor in itself and also evidence of resilience. 


\section{Resilience}

\section{Definition}

Resilience is difficult to define (Luthar 2000; Grotberg 2003), being differingly conceptualised as a process and as an outcome, as a property that individuals possess and as something that may or may not develop and change, as a global (set of) characteristics and as an attribute which may show itself differently in different domains. Resilience can mean: better-than-expected developmental outcomes; competence when under stress; or positive functioning indicating recovery from trauma.

Nevertheless, psychological resilience has been defined as 'the capacity to adapt to and overcome stress and adversity' (American Psychological Association 2014). Gilligan (1997) has similarly defined resilience as 'the capacity to transcend adversity'. Both of these definitions accept that being resilient does not mean going through life without experiencing stress and pain. Rather, individuals demonstrate resilience when they can face difficult experiences and rise above them without major difficulty. Hence, 'resilience' has a number of core characteristics:

- it is a process rather than a trait

- it is not a rare ability but can be found in many (probably most) individuals

- people may be resilient in some areas and not in others

- it is also not something that people are either born with or not; it can be learned and developed across the lifespan through cognitive processing, self-management skills and knowledge

- supportive relationships (with parents, peers and others), as well as cultural beliefs and traditions, are all crucial.

In sum, it is a fluid process; it is not a single variable. It is open to change over time and according to circumstance, and it is influenced by a range of individual, family, environmental and societal variables.

\section{Concepts and theories of resilience}

Angell (2014) suggests that thinking about resilience can be traced back at least to Freud and his successors in their thinking about adaptation to stress; and it is the case that there are many overlaps with ideas such as existential psychology and 'will to meaning' (Frankl 1959), hardiness (Kobasa 1982), post-traumatic growth (Tedeschi 2004; Joseph 2012), recovery in mental health (Velleman 2007b; Slade 2010) and positive psychology (Seligman 2011). Furthermore, others are considering resilience in many areas of study, such as in those at suicide risk (Johnson 2011) and those experiencing mental health issues (Southwick 2011).

The concept of and theories about resilience provide a framework for studying the interplay between risk and protective factors. Research (e.g. Daniel 2002) has suggested that the three fundamentals of resilience are:

- a secure base (a sense of belonging and security)

- good self-esteem (an internal sense of worth and competence)

- a sense of self-efficacy (a sense of mastery and control, along with an accurate understanding of personal strengths and limitations).

These fundamentals are influenced by a wide range of elements, based on three factors: attributes which the young people themselves hold, aspects of their families, and characteristics of their wider social environments (Jaffee 2007). These have been further broken down into key domains which underpin resilience: secure family attachments, education, friendships, talents and interests, positive values, and social competencies (Daniel 2002).

As was stressed in both our 2007 article and the section on definitions above, it is important not to conceptualise resilience as an all-or-nothing phenomenon, nor as being fixed in time. Further, the domains in which resilience can be observed need to be specified (Goldstein 2013): an individual may demonstrate major strengths in some areas and yet have difficulties in others. Sometimes the appearance of resilience can mask other difficulties, and a factor or process which may be protective in one domain may be less protective in another. For example, something which may operate positively and suggest resilience, such as doing well at school, may mask problems in other areas, whereas something which may be perceived negatively, such as taking on a caring role at too young an age (maybe at the expense of school attendance or performance), may be viewed positively by a child because it protects them and/or their family from harms in other areas (Sawyer 2012). In Velleman \& Orford (1999) we drew attention to how 'avoidance' was an effective coping strategy for a child living with a violent or abusive parent, but one which might be far less effective once that child grew to adulthood. It has also been noted that some children from high adversity backgrounds (e.g. living with parental substance misuse) are more likely to do well and be high achievers (Forrester 2011).

The key points relating to the relationship between resilience and the range of factors which may serve to protect children of problem substance users are shown in Box 3. 


\section{Modifying the impact: what can practitioners do?}

\section{Creating resilience}

As we argued in our previous article, because resilience is the product of an interaction between the individual and their social context, it is potentially open to influence by designing prevention strategies focused on increasing positive factors instead of solely reducing risk.

This suggests looking at the interaction between children and their social contexts (including home, school and communities), understanding parental behaviours, focusing on positive coping, and finding positive social support. A key advantage of focusing on resilience is that it shifts attention from a focus on problems to developing a child's strengths.

\section{In theory}

Practitioners should be able to promote resilience by primarily working on developing protective factors in both young people and their families, as well as working on reducing risk factors. We and others have stated that instead of concentrating solely on parental presenting problems (e.g. the risk to a child of a parent misusing substances), practitioners should focus far more on enabling the child and the family to develop protective factors, and thus enhance resilience. For example, Moe et al (2007) identified three ways in which practitioners could help children to develop resilience:

- providing children with a venue in which to express their feelings;

- educating them about substance misuse;

- showing them that there are other ways to live.

This links with practitioners focusing on and working with the child's 'active agency' in adopting coping strategies and seeking support. O'Connor et al (2014), in their evaluation of a service for high-risk children exposed to parental substance misuse, highlighted that practitioners should 'avoid unhelpful binaries focusing on either the child's or the adult's needs' - although successfully bridging this divide continues to be a perennial problem.

In work which focused on the children of parents with a mental illness, Hosman et al (2009) and van Doesum \& Hosman (2009) developed a model which could also be used to aid assessment and intervention with a wide range of families affected by parental substance misuse (and/or domestic violence and abuse and/or parental mental illness - other problems which may also be present). Similarly, a comprehensive and holistic childcentred approach to guide practitioners in their work with children and young people, including
B0X 3 Protective factors and processes, and resilience: key points
- It is not a foregone conclusion that children living with parental problematic substance use (even if associated with other parental or family problems such as parental mental illness or domestic violence) will be adversely affected and the potential to be resilient.

- Resilience is a fluid process which is not based on a single variable and which is open to change over time, and according to circumstance and the influence of a range of individual, family, environmental and societal variables.

- Protective factors and processes can reduce the likelihood of poor outcomes for children and build their resilience. There are no straightforward and generalisable associations between a protective factor and a better-than-expected outcome or resilience. A protective factor is not

- Protective factors are influenced by their interactions with each other, by the number and severity of risk factors, and by variables such as age, development, have poor outcomes. Many children have necessarily the opposite of a risk factor. gender and culture. The most important protective factors are believed to be the presence of a significant caring adult in the child's life, the child's own temperament, engagement with school and other community activities, positive parenting and peer support, and a swift resolution to parental problems. Relationships, particularly with parents (and/or other primary caregivers) and particularly in a child's early years, are thought to be the 'roots of resilience'.

- Parental gender will influence the role of a protective factor. It is also believed that research has not done enough to consider the specific impact on children, and fathering, where paternal problems are present.

- Resilience may be complex. A protective factor in youth may not operate as such in adulthood; the same factor (e.g. avoidance as a coping strategy) may be both beneficial and detrimental at different times and stages.

(Adapted from Templeton 2013: p. 40) those who are vulnerable and living with distressing and complex issues such as parental substance misuse, has been developed in Scotland (Scottish Government 2010, 2012). The aims of the 'Getting it right for every child' (GIRFEC) model are that all children:

- will feel confident about the help they are getting

- will understand what is happening and why

- have been listened to carefully and their wishes have been heard and understood

- are appropriately involved in discussions and decisions that affect them

- can rely on appropriate help being available as soon as possible

- will have experienced a more streamlined and coordinated response from practitioners.

The ultimate aim is to ensure that children grow and achieve in eight areas of well-being: safe, active, healthy, respected, achieving, responsible, nurtured and included.

There is a similar approach in England, guided by the Common Assessment Framework, which offers a multi-agency framework for the early identification of needs and guidance on how to best meet them (Children's Workforce Development Council 2009). 


\section{In practice}

Our 2007 article concluded with the statement: 'We believe that it is relatively clear how professionals can help families to reduce risk, develop protective factors and promote resilience in young people. However, further work is needed to encourage and train professionals to use this knowledge to work in a more focused and integrated way, looking at the full range of a child's needs within a broader context' (Velleman 2007a). How far have professionals moved in using this knowledge to promote resilience?

\section{Guidance and interventions}

There has been a noticeable growth in services and interventions to support children affected by parental substance misuse, all of which have incorporated some of the ideas about targeting protective factors and building resilience into their delivery models (while also addressing and prioritising risk as required) (e.g. Forrester 2008, 2016; Adamson 2012; Harwin 2014; O'Connor 2014; Templeton 2014a,b).

To support these developments various guidance and toolkits have been produced, such as a toolkit to promote work with 'alcohol hidden harm' in England (funded by Comic Relief to consider what worked best for the children of parental alcohol misusers: www.alcoholhiddenharmtoolkit. org.uk) or one developed in Scotland to support practitioners working with parental problem alcohol and drug use (Whittaker 2014).

Although the evaluations of these innovative interventions report encouraging findings and highlight the potential for focusing on protective factors and processes with a view to building resilience, this work is still in its infancy, and much more research in this area is needed, work which should include more rigorous methodological approaches (such as control groups) and longerterm follow-ups. Furthermore, despite the advances in this area, the scarcity of service provision has been repeatedly highlighted (Clay 2010; Adamson 2012; Hill 2015).

Alcohol Hidden Harm Project An evaluation of the Alcohol Hidden Harm Project (McWhirter 2012) identified how services could best target protective factors to build resilience in children. This includes: operating in a child-centred and familyfocused way, delivering a range of therapeutic services flexibly and non-judgementally, building children's social networks, and considering the qualities which services need to work in such a way (e.g. staff selection, leadership, community partnerships and evaluation). When services work in such ways, children can benefit from feeling less isolated and better supported because they have the opportunity to (for example) share how they feel, meet others with similar experiences and engage in diversionary activities.

This multisite evaluation recommended that support to children should not necessarily be timelimited, something which O'Connor et al (2014) also recognised as important in the evaluation of another service for children affected by a number of coexisting problems and requiring the involvement of child protection services. O'Connor et al also emphasised the importance of immediate, and briefer, intervention at times of crisis.

\section{Services for children}

Work has attempted to understand what children look for from services, and what characteristics of help and support are most important. One clear finding is that many children want to have some control over what they keep private/secret, and this is obviously important when thinking about how to help these children (Adamson 2012; Hill 2013, 2015; O'Connor 2014).

\section{Adopting resilience in national policy}

The growing body of evidence from research and evaluation studies demonstrates that intervening with at-risk children and young people, focusing on protective factors and attempting to develop resilience as opposed to simply working to alleviate risk factors, are helpful. One key task is to root these initiatives within routine practice as opposed to seeing them simply as part of research studies (Prince-Embury 2013; Angell 2014). Practitioners should also be aware of the different risk and protective factors which might affect children of different ages (e.g. Cleaver 2011).

One major way of ensuring this would be for national policy to adopt a resilience approach. Certainly across the UK over the past decade there have continued to be improvements, with policy starting to recognise and respond to children affected by parental substance misuse, although there is variation between the UK administrations (Hill 2013). However, the progress which has been made has focused largely on parental drug misuse, meaning that major policy limitations remain with regard to parental alcohol misuse (Adamson 2012). Furthermore, policy has also tended to focus on those children and families deemed to be most at risk (such as those with child protection involvement or from so-called 'troubled families'), and has viewed children as a homogeneous group rather than as a population with diverse experiences and needs. Finally, policy has not yet sufficiently embraced ideas of resilience and how those can be 
incorporated into national and local policy, and associated practice.

\section{What have we learned since 2007 and where are there still gaps?}

The research undertaken in the past decade has built on the literature that we reviewed in 2007 . Knowledge has continued to advance, although significant gaps remain.

At the start of this article we summarised what is known now about the numbers of children who are affected by parental substance misuse in the UK. Previous work had defined numbers by concentrating on children of parents in treatment. Manning et al's (2009) work, based on analysis of multiple national survey results, showed that numbers were substantially higher than had previously been thought. Nevertheless, there has been little new work in this area, and hence a significant gap remains, especially as there has been an increase in use of novel psychoactive substances in this time. Understanding prevalence is critical for developing appropriate policy and practice responses to this population and to subgroups within it, which may have different experiences and needs.

Some of the recent work which we have reviewed supports existing knowledge about how children are affected by parental substance misuse (including the risk factors that they face), and about the protective factors, protective processes and evidence of resilience which can reduce the likelihood that children will experience poor outcomes. Where work in recent years has particularly added to what was already known is in understanding the complexities associated with protective factors and resilience. Related to this, we are gaining greater understanding of the active role which children themselves play in responding to their circumstances and how important this is in working with children to develop the help and support that they need.

Further research is needed to understand what areas of resilience are most important to target (e.g. psychological or behavioural components), and whether there are differences (in the function of protective factors and hence the ability to build resilience) according to key variables such as gender or age (Cleaver 2011), living with alcohol or drug problems (Russell 2006), including where there may be differences between drug types, or mental health problems (Cleaver 2011), maternal or paternal problems (Scaife 2008), and how many risk factors or protective factors a child is exposed to (Templeton 2013). Such work also needs to bear in mind that an individual's resilience may change over time, with factors or processes operating positively or negatively at different developmental or life stages (Velleman 2007a; Backett-Milburn 2008), indicating the need for much more longitudinal research.

We have also learned that both policy and practice have made inroads in recognising this population as one in need of prioritisation, and we have seen the emergence of a number of different and promising ways of supporting which have incorporated ideas of resilience into service models. However, the work we have reviewed has also highlighted the considerable challenges which practitioners, service providers and commissioners face in better meeting the needs of children.

Finally, we have reported that there has been growth and development in services; yet there are still pressing needs for more services; for their effectiveness to be more rigorously evaluated (both in the long term and including their costeffectiveness); and for services and interventions to more clearly target protective factors/processes and build sustainable resilience. For services to be able to do this, they themselves need to be well supported/funded and sustainable. Instead, many services are funded in the short term as "pilot projects' with no clarity over how sustained funding might be forthcoming if the 'pilot' demonstrates success. Even in the few geographical areas where services are provided, there is little choice available, and hence there is also a need for choice and diversity. Further, most services focus on children 'at risk'; there is also a need for services to meet the full spectrum of need, offering help to children in need of support as well as those at risk of significant harm (Adamson 2012; Hill 2013).

\section{Conclusions}

It is clear that supporting children and families affected by parental problematic substance use requires an understanding of resilience - and of both risk and protective factors - at the individual, family and environmental levels. There are a number of protective factors and processes which can mitigate against children having poor outcomes as a result of their experiences of parental substance misuse and can build children's resilience to such adversities. It is therefore vital that practitioners who engage with these children and their families develop a full understanding of resilience and of what protective factors and processes may be present or available that can be part of the response and help offered. Teaching about the effects on children and how to develop resilience needs to become part of core training for psychiatrists, social workers and other front-line professionals. 


\section{MCQ answers}

$\begin{array}{lllll}1 \mathrm{c} & 2 \mathrm{~d} & 3 \mathrm{a} & 4 \mathrm{c} & 5 \mathrm{c}\end{array}$
Although there has been progress made in understanding and modifying the impact of parental substance misuse, and of how this can be translated into policy and practice, there is still much to learn and understand. There is an urgent need to incorporate ideas of protective factors/ processes and resilience into the routine clinical practice of a wide range of practitioners who will come into contact with children affected by parental substance misuse.

\section{References}

Adamson J, Templeton L (2012) Silent Voices: Supporting Children and Young People affected by Parental Alcohol Misuse. Office of the Children's Commissioner for England.

American Psychological Association (2014) The Road to Resilience. APA.

Angell E (2014) Psychological resilience in clinical practice: a discussion paper. Clinical Psychology Forum, 260: 12-5.

Backett-Milburn K, Wilson S, Bancroft A, et al (2008) Challenging childhoods: young people's accounts of 'getting by' in families with substance use problems. Childhood, 15: 461-79.

Bernays S, Houmoller K, Rhodes T, et al (2011) See Me, Not Just the Problem: Hiding, Telling and Coping with a Difficult Family Life. London School of Hygiene and Tropical Medicine

Brandon M, Bailey S, Belderson P, et al (2009) Understanding Serious Case Reviews and their Impact: A Biennial Analysis of Serious Case Reviews 2005-7. Department for Children, Schools and Families.

Brandon M, Bailey S, Belderson P (2010) Building on the Learning from Serious Case Reviews: A Two-Year Analysis of Child Protection Database Notifications 2007-2009: Research Brief. Department for Education.

Children's Workforce Development Council (2009) Early Identification, Assessment of Needs and Intervention. CWDC.

Clay D, Corlyon J (2010) A review of services for children and young people with drug-misusing carers. In Responding to Drug Misuse: Research and Policy Priorities in Health and Social Care (ed S MacGregor): 179-89. Routledge.

Cleaver H, Nicholson D, Tarr S, et al (2007) Child Protection, Domestic Violence and Parental Substance Misuse: Family Experiences and Effective Practice. Jessica Kingsley.

Cleaver H, Unell I, Aldgate J (2011) Children's Needs - Parenting Capacity. Child Abuse: Parental Mental IIIness, Learning Disability, Substance Misuse, and Domestic Violence (2nd edn). TSO (The Stationery Office).

Daniel B, Wassell S (2002) Assessing and Promoting Resilience in Vulnerable Children (Vols 1, 2 and 3). Jessica Kingsley.

European Monitoring Centre for Drugs and Drug Addiction (2015) New Psychoactive Substances in Europe. An Update from the EU Early Warning System. Publications Office of the European Union.

Forrester D, Harwin J (2007) Parental substance misuse and child welfare: outcomes for children two years after referral. British Journal of Social Work, 38: 1518-35.

Forrester D, Copello A, Waissbein C, et al (2008) Evaluation of an intensive family preservation service for families affected by parental substance misuse. Child Abuse Review, 17: 410-26.

Forrester D, Harwin J (2011) Parents Who Misuse Drugs and Alcohol: Effective Interventions in Social Work and Child Protection. WileyBlackwell.

Forrester D, Holland S, Williams A, et al (2016) Helping families where parents misuse drugs or alcohol? A mixed methods comparative evaluation of an intensive family preservation service. Child \& Family Social Work, 21: $65-75$.

Frankl V $(1959,2011)$ Man's Search for Meaning. Rider (Random House).

Fraser C, Mclntyre A, Manby M (2009) Exploring the impact of parental drug/alcohol problems on children and parents in a Midlands county in 2005/06. British Journal of Social Work, 39: 846-66.
Gilligan R (1997) Beyond permanence? The importance of resilience in child placement practice and planning. Adoption and Fostering, 21: 12-20.

Goldstein S, Brooks R (eds) (2013) Handbook of Resilience in Children (2nd edn). Springer.

Grotberg EH (2003) What is resilience? How do you promote it? How do you use it? In Resilience for Today: Gaining Strength from Adversity (ed E Grotberg): 1-30. Praeger

Harwin J, Madge N, Heath S (2010) Children affected by Parental Alcohol Problems (ChAPAPS). A Report on the Research, Policy, Practice and Service Development relating to ChAPAPs across Europe. Brunel University \& ENCARE Network.

Harwin J, Alrouh B, Ryan M, et al (2014) Changing Lifestyles, Keeping Children Safe: An Evaluation of the First Family Drug and Alcohol Court (FDAC) in Care Proceedings. Brunel University.

Hill $L$ (2013) In their own right: developing confidential services for children and young people affected by parental alcohol and drug use. In Emerging Perspectives on Substance Misuse (ed W Mistral): 118-33. Wiley Blackwell.

Hill L (2015) 'Don't make us talk!': listening to and learning from children and young people living with parental alcohol problems. Children and Society, 29: 344-54.

Holmila M, Itapuisto M, Ilva M (2011) Invisible victims or competent agents: opinions and ways of coping among children aged 12-18 years old with problem drinking parents. Drugs: Education, Prevention and Policy, 18: $179-86$.

Horgan J (2011) Parental Substance Misuse: Addressing its Impact on Children. A Review of the Literature. National Advisory Council on Drugs.

Hosman C, van Doesum K, van Santvoort F (2009) Prevention of emotional problems and psychiatric risks in children of parents with a mental illness in the Netherlands: I. The scientific basis to a comprehensive approach. Australian e-Journal for the Advancement of Mental Health, 8: 250-63.

Houmoller K, Bernays S, Wilson S, et al (2011) Juggling Harms: Coping with Parental Substance Misuse. London School of Hygiene and Tropical Medicine.

Jaffee SR, Caspi A, Moffitt TE, et al (2007) Individual, family and neighbourhood factors distinguish resilient from nonresilient maltreated children: a cumulative stressors model. Child Abuse and Neglect, 31: 231-53

Johnson J, Wood A, Gooding P, et al (2011) Resilience to suicidality: the buffering hypothesis. Clinical Psychology Review, 31: 563-91.

Joseph S (2012) What doesn't kill us... The Psychologist, 25: 816-9.

Kelley M, Braitman A, Henson J, et al (2010) Relationships between depressive symptoms and parent and peer attachment in adult children of alcoholics. Journal of Orthopsychiatry, 80: 204-12.

Kobasa S, Maddi S, Kahn S (1982) Hardiness and health: a prospective study. Journal of Personality and Social Psychology, 42: 168-77.

Luthar S, Cicchetti D, Becker B (2000) The construct of resilience: a critical evaluation and guidelines for future work. Child Development, 71 : 543-62

Manning V, Best DW, Faulker N, et al (2009) New estimates of the number of children living with substance misusing parents: results from UK national household surveys. BMC Public Health, 9: 377.

Manning V (2011) Estimates of the Number of Infants (Under the Age of One Year) Living with Substance Misusing Parents. NSPCC.

Mariathasan J, Hutchinson D (2010) Children Talking to ChildLine about Parental Alcohol and Drug Misuse. NSPCC

McWhirter J, Madil E (2012) Alcohol's Hidden Harm: A Three Year Cohort Study (Key Learning). Comic Relief.

Moe J, Johnson J, Wade W (2007) Resilience in children of substance users: in their own words. Substance Use and Misuse 42: 381-98.

Munro E (2011) The Munro Review of Child Protection: Final Report. TSO (The Stationery Office)

O'Connor L, Forrester D, Holland S, et al (2014) Perspectives on children's experiences in families with parental substance misuse and child protection interventions. Children and Youth Services Review, 38: 66-74. 
Prince-Embury S, Saklofske D (eds) (2013) Resilience in Children, Adolescents, and Adults: Translating Research into Practice. Springer.

Redelinghuys J, Dar K (2008) A survey of parents receiving treatment for substance dependence: the impact on their children. Journal of Substance Use, 13: 37-48

Ronel N, Levy-Cahana M (2011) Growing-up with a substance-dependent parent: development of subjective risk and protective factors. Substance Use and Misuse, 46: 608-19.

Russell P (2006) A Matter of Substance? Alcohol or Drugs: Does it make a Difference to the Child? Aberlour Child Care Trust \& The Scottish Association of Alcohol and Drug Action Teams.

Sawyer E, Burton S (2012) Building Resilience in Families Under Stress: Supporting Families Affected by Parental Substance Misuse and/ or Mental Health Problems - A Handbook for Practitioners (2nd edn). National Children's Bureau.

Scaife V (2008) Maternal and paternal drug misuse and outcomes for children: identifying risk and protective factors. Children and Society, 22: 53-62.

Scottish Government (2010) A Guide to Implementing Getting it Right for Every Child: Messages from Pathfinders and Learning Partners. The Scottish Government.

Scottish Government (2012) A Guide to Getting it Right for Every Child. The Scottish Government

Seligman M (2011) Flourish: A Visionary New Understanding of Happiness and Well-Being. Free Press.

Slade M (2010) Mental illness and well-being: the central importance of positive psychology and recovery approaches. BMC Health Service Research, 10: 26

Southwick S, Litz B, Charney D, et al (eds) (2011) Resilience and Mental Health: Challenges Across the Lifespan. Cambridge University Press.

Tedeschi R, Calhoun L (2004) Posttraumatic growth: conceptual foundations and empirical evidence. Psychological Inquiry, 15: 1-18,

Templeton L, Velleman R, Hardy E, et al (2009) Young people living with parental alcohol misuse and parental violence: 'No-one has ever asked me how I feel in any of this'. Journal of Substance Use, 14: 139-50.
Templeton L (2013) Building Resilience and Reducing Risks in Children Affected by Serious Untreated Parental Mental IIIness, Problematic Substance Use and Domestic Violence. Final Report. Vancouver Costal Health Authority.

Templeton L (2014a) Supporting families living with parental substance misuse: the M-PACT (Moving Parents and Children Together) programme. Child and Family Social Work, 19: 76-88.

Templeton L, Sipler E (2014b) Helping children with the Steps to Cope intervention. Drugs and Alcohol Today, 14: 126-36.

Torvik FA, Rognmo K, Ask H, et al (2011) Parental alcohol use and adolescent school adjustment in the general population: results from the HUNT study. BMC Public Health, 11: 706.

van Doesum K, Hosman C (2009) Prevention of emotional problems and psychiatric risks in children of parents with a mental illness in the Netherlands: II. Interventions. Australian e-Journal for the Advancement of Mental Health, 8: 264-76.

Velleman R, Orford J (1999) Risk and Resilience: Adults who Were the Children of Problem Drinkers. Harwood.

Velleman R, Templeton L (2007a) Understanding and modifying the mpact of parents substance misuse on children. Advances in Psychiatric Treatment, 13: 79-89.

Velleman R, Davis E, Smith G, et al (eds) (2007b) Changing Outcomes in Psychosis: Collaborative Cases from Users, Carers and Practitioners. Blackwell.

Velleman R, Reuber D, Klein M, et al (2008) Domestic abuse experienced by young people living in families with alcohol problems: results from a cross-European study. Child Abuse Review, 17: 387-409.

Velleman R (2009a) Influences on How Children and Young People Learn About and Behave Towards Alcohol: A Review of the Literature for the Joseph Rowntree Foundation (Part One). JRF.

Velleman R (2009b) Alcohol Prevention Programmes: A Review of the Literature for the Joseph Rowntree Foundation (Part Two). JRF.

Werner E, Johnson J (2004) The role of caring adults in the lives of children of alcoholics. Substance Use and Misuse, 39: 699-720.

Whittaker A (2014) Practitioner Toolkit: Getting it Right for Children and Families Affected by Parental Problem Alcohol and Drug Use. NHS Lothian.
MCQs

Select the single best option for each question stem

1 In the UK:

a the number of children affected by parental substance problems has decreased over the past decade

b we have a clear understanding of how many children are affected

c children face increased risk of poor outcomes if other family difficulties, such as mental health difficulties or domestic abuse, are also present

$\mathrm{d}$ more children are affected by parental drug misuse than parental alcohol misuse

e no more than $10 \%$ of babies under the age of 1 will have been exposed to at least one type of serious parental risk.

\section{Parental substance misuse problems:}

a generally affect only the misuser, and not their children

b reduce the likelihood of violence in the family home

c are not likely to lead to emotional and mental health problems in children $\mathrm{d}$ are often associated with disharmony, aggression and violence, and these all raise the risks of negative outcomes for children

e not the existence of problematic parenting or the frequent absence of a stable adult figure, give rise to negative outcomes for children.

3 Protective factors:

a balance out risk factors, may be inconsistent with some risk factors and may strongly protect, even if other areas of life are very risky

b are much more difficult to create or change than risk factors

c are often useful in the short term, as a way of surviving 'in the moment', and in the long term

$d$ are especially important if they are related to internal characteristics such as 'agency', as opposed to ones located within the family, particularly related to parenting and parentchild relationships

e are all external to the child: children are not active agents in adopting coping strategies or seeking support.

\section{Resilience is}

a a static trait, internal to the individual

b a process that is rarely open to influence

c different from protective factors, which increase the chances of a child being more resilient

d a defence mechanism created by a child who feels worthless, unwanted and lacks confidence

e extremely difficult to encourage if it is not there innately.

5 Interventions with children who live in difficult circumstances should:

a wait until a crisis is reached and damage is apparent

b focus solely on reducing risk factors

c start as early as possible to promote factors associated with greater resilience

$\mathrm{d}$ be made only by specialist child and adolescent psychiatrists

e involve the professional making a very longstanding commitment to working with the child and their family. 